DOI: 10.1002/chem.200801337

\title{
Diphosphinine Derivatives of Terpyridine: A New Class of Neutral $\pi$-Accepting PNP-Pincer Ligands
}

\author{
Christian Müller, ${ }^{[a]}$ Evgeny A. Pidko, ${ }^{[a]}$ Martin Lutz, ${ }^{[b]}$ Anthony L. Spek, ${ }^{[b]}$ and \\ Dieter Vogt ${ }^{[a]}$
}

Phosphinines (phosphabenzenes, phosphorins), the higher homologues of pyridines are low-coordinated phosphorus compounds that possess significantly different steric and electronic properties compared to common ligands based on trivalent phosphorus. ${ }^{[1,2]}$

We have recently started to investigate the preparation of functionalized phosphinines via the pyrylium salt route, originally described by Märkl for the synthesis of 2,4,6-triphenylphosphinine. ${ }^{[1 \mathrm{a}]}$ It turned out that this procedure allowed us to introduce substituents into specific positions of the heterocyclic framework; a feature which is essential for ligand design and their potential application in homogeneous catalytic reactions. In this way a variety of donor-functionalized and axially chiral monophosphinines, as well as a trans-coordinating diphosphinine have been designed and prepared by us lately. ${ }^{[3,4]}$

We have now extended this modular approach to the synthesis of the tridentate pyridyl-bridged diphosphinine $\mathbf{1}$ (Figure 1). ${ }^{[2 a]}$ This compound resembles not only a diphosphinine analogue of the well-known $2,2^{\prime}: 6^{\prime}, 2^{\prime \prime}$ terpyridine (tpy) but represents at the same time a new class of neutral $\pi$-accepting PNP-pincer ligands.

Reaction of commercially available 2,6-diacetylpyridine with four equivalents of benzylidene-acetophenone in the presence of $\mathrm{HBF}_{4} \cdot \mathrm{Et}_{2} \mathrm{O}$ at $T=70^{\circ} \mathrm{C}$ affords the bis-pyrylium salt 2 (Scheme 1) ${ }^{[5]}$ Compound 2 was obtained as a yellow solid after recrystallization from hot methanol in $56 \%$ yield.

[a] Dr. C. Müller, Dr. E. A. Pidko, Prof. Dr. D. Vogt

Department of Chemical Engineering and Chemistry

Schuit Institute of Catalysis, Eindhoven University of Technology

5600 MB Eindhoven (The Netherlands)

Fax: $(+31) 40-245-5054$

E-mail: c.mueller@tue.nl

[b] Dr. M. Lutz, Prof. Dr. A. L. Spek

Bijvoet Center for Biomolecular Research

Crystal and Structural Chemistry, Utrecht University, Padualaan 8 3584 CH Utrecht (The Netherlands)

Supporting information for this article is available on the WWW under http://dx.doi.org/10.1002/chem.200801337.
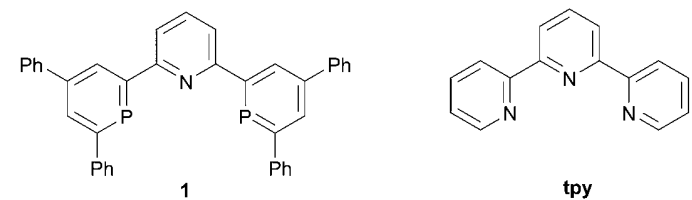

Figure 1. Tridentate neutral PNP-pincer ligand $\mathbf{1}$ in comparison with tpy.

We assume that the recrystallization procedure affords the non-protonated compound $\mathbf{2}$ and not the analogous pyridinium salt as also observed before for the related 2-pyridyl-4,6diphenyl pyrylium tetrafluoroborate. ${ }^{[3 \mathrm{~d}]}$ In fact, the triplet at $\delta=8.1 \mathrm{ppm}\left({ }^{3} J_{\mathrm{H}, \mathrm{H}}=8.0 \mathrm{~Hz}\right)$ in the ${ }^{1} \mathrm{H}$ NMR spectrum of 2 $\left(\mathrm{CD}_{3} \mathrm{CN}\right)$ is indicative for the resonance of a proton in $\mathrm{H}_{\gamma}$ position of a pyridine-ring, rather than of a pyridinium ion. The elemental analysis further confirms the presence of $\mathbf{2}$ rather than of $\mathbf{2} \cdot \mathrm{HBF}_{4}$.

Reaction of the bis-pyrylium salt 2 with excess P$\left(\mathrm{CH}_{2} \mathrm{OH}\right)_{3}{ }^{[6]}$ only leads to traces of the desired product as confirmed by ${ }^{31} \mathrm{P}$ NMR spectroscopy. However, 2 was successfully transformed into the corresponding pyridyl-bridged diphosphinine 1 by reaction with $\mathrm{P}\left(\mathrm{SiMe}_{3}\right)_{3}{ }^{[7]}$ in acetonitrile at $T=80^{\circ} \mathrm{C}$ according to Scheme 1 . Compound $\mathbf{1}$ was obtained as a yellow solid in $24 \%$ yield after column chroma-

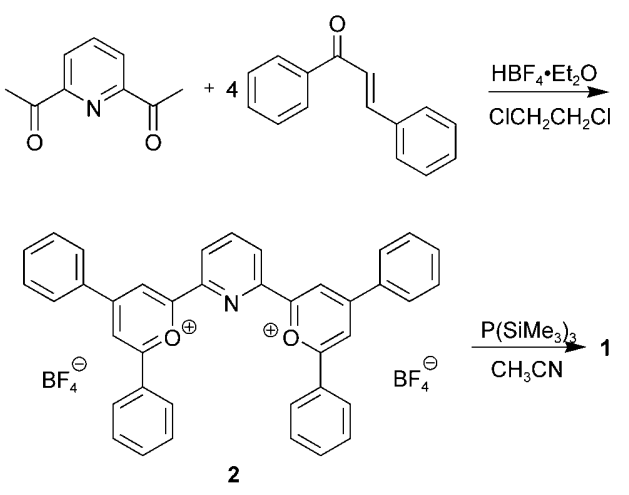

Scheme 1. Synthesis of PNP-pincer $\mathbf{1}$ 
tography and shows the typical downfield resonance for phosphinines at $\delta=188.2 \mathrm{ppm}$ in the ${ }^{31} \mathrm{P}$ NMR spectrum $\left(\mathrm{C}_{6} \mathrm{D}_{6}\right)$. Any attempt to characterize $\mathbf{1}$ also crystallographically has failed so far due to the poor quality of the yellow crystalline needles obtained after recrystallization of $\mathbf{1}$ from hot acetonitrile.

Diphosphinine $\mathbf{1}$ resembles a terpyridine analogue in which two of the three pyridine moieties have been substituted by the homologous aromatic phosphinine heterocycle. In contrast to the well studied neutral PNP-pincer ligands of the type I (Figure 2) containing predominantly $\sigma$-donor groups, the tridentate ligand $\mathbf{1}$ consists both of a $\sigma$-donor pyridine group as well as two $\pi$-acceptor phosphinine donors due to the incorporation of the formally $\mathrm{sp}^{2}$-hybridized phosphorus atom into the aromatic ring system. ${ }^{[8]}$

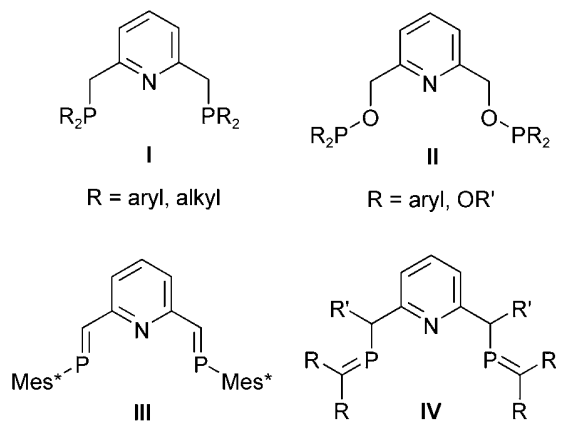

Figure 2. PNP-pincer ligands with different electronic properties.

The electronic properties of $\mathbf{1}$ were evaluated by means of DFT calculations and a selection of relevant frontier orbitals is illustrated in Figure 3. ${ }^{[9,10]}$ The $\mathrm{LUMO}^{+1}$ and LUMO, which are close in energy enable the phosphinine moieties to act as strong $\pi$-acceptors upon coordination to a metal center. Furthermore, the $\mathrm{HOMO}$ and $\mathrm{HOMO}^{-1}$ can participate in both $\sigma$-donation from the nitrogen atom and $\pi$-donation from the phosphorus atoms. The low-lying $\mathrm{HOMO}^{-3}$ and $\mathrm{HOMO}^{-4}$ represent the lone-pairs at the donor atoms for participation mainly in $\sigma$-bonding with a metal center.

As a matter of fact neutral PNP-pincers with such electronic properties are very rare. Examples are phosphinites and phosphites based on bis(hydroxymethyl)pyridine (Figure 1, II) although these systems tend to coordinate in an intermolecular fashion towards a metal center due to the more flexible side arms. Moreover, the nitrogen donor in these complexes usually does not participate in any bonding to the metal center as a result of the additional oxygenspacer. The most closely related systems to compound $\mathbf{1}$ are the bis-iminopyridine analogue 2,6-bis(2-phosphaethenyl)pyridine (Figure 2, III), first reported by Geoffroy et al. ${ }^{[11]}$ and bis-phosphaalkene-pyridines of type IV (Figure 2) described by Nieke and co-workers. ${ }^{[12]}$

We were further interested in the coordination chemistry of $\mathbf{1}$ towards $\mathrm{Cu}^{\mathrm{I}}$ as PNP-type pincer ligands of type $\mathbf{I}$ (Figure 2) have recently been shown by our group to undergo facile complexation upon reaction with a suitable $\mathrm{Cu}^{\mathrm{I}}$
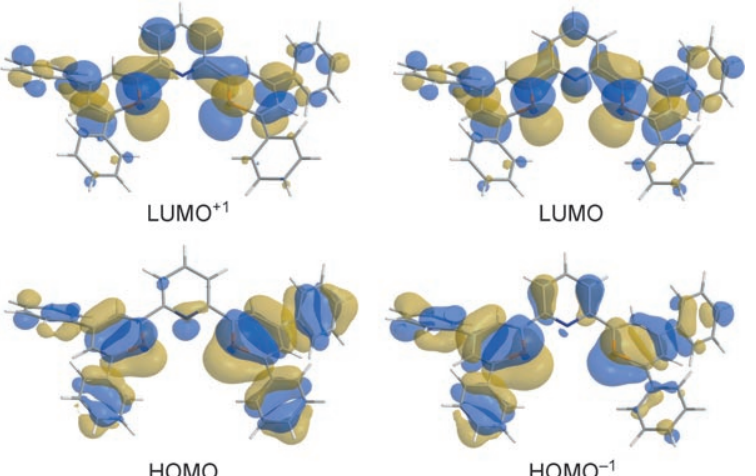

LUMO

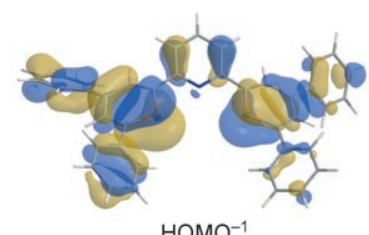

$\mathrm{HOMO}^{-1}$

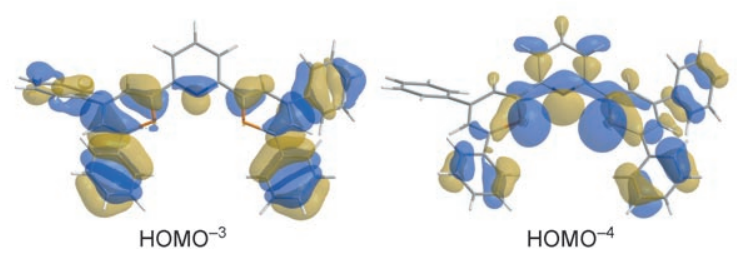

Figure 3. Selected frontier orbitals of PNP-pincer ligand $\mathbf{1 .}$

source. ${ }^{[13]}$ On the other hand, structural informations on discrete terpyridine- $\mathrm{Cu}^{\mathrm{I}} \mathrm{X}$ complexes $(\mathrm{X}=$ halogen $)$ have, to the best of our knowledge, not been reported to date in literature, although these species have been postulated in atom-transfer radical polymerization reactions. ${ }^{[14]}$ The only structurally characterized $\mathrm{Cu}^{\mathrm{I}}(\mathrm{tpy})$ complexes are cationic complexes containing either an extremely bulky terpyridine derivative, which induces a strongly perturbed, almost square-planer $\mathrm{Cu}^{\mathrm{I}}$ coordination geometry or an additional $\mathrm{PPh}_{3}$ ligand leading to a trigonal-bipyramidal $\mathrm{Cu}^{\mathrm{I}}$ coordination geometry. ${ }^{[15]}$ Also, a neutral one-dimensional coordination polymer $\left[\mathrm{Cu}_{2}(\mathrm{~L})[\mu-\mathrm{I})_{2}\right]_{n} \quad(\mathrm{~L}=4$ 'pyridyl terpyridine; pytpy) has been reported, containing hexacoordinated, distorted square-pyramidal $\mathrm{Cu}^{\mathrm{I}}$ centers and forming one-dimensional zigzag chains. ${ }^{[16]}$ The preferred meridial coordination mode of this tridentate nitrogen-ligand results from the $\mathrm{sp}^{2}$ hybridization of both carbon and nitrogen atoms causing a directional orientation of the nitrogen lone pairs in the plane of the heterocycles. Consequently, terpyridine preferentially accommodates transition-metal centers with squareplanar or octahedral, rather than tetrahedral coordination geometries, such as $\mathrm{Cu}^{\mathrm{I}}{ }^{[17]}$

Reaction of 1 with equimolar amounts of $\mathrm{CuBr}\left(\mathrm{SMe}_{2}\right)$ in $\mathrm{CH}_{2} \mathrm{Cl}_{2}$ does lead instantaneously and quantitatively to the corresponding $\mathrm{PNP}-\mathrm{CuBr}$ complex $\mathbf{3}$, as confirmed by ${ }^{31} \mathrm{P}$ NMR spectroscopy (Scheme 2).

Compound 3 slowly precipitates as an orange solid from the reaction mixture upon standing. It shows a broad resonance at $\delta=158.5 \mathrm{ppm}$ in the ${ }^{31} \mathrm{P} \mathrm{NMR}$ spectrum $\left(\mathrm{CD}_{2} \mathrm{Cl}_{2}\right)$, which is in the typical range for transition metal complexes of phosphinines. Orange crystals suitable for X-ray diffraction were obtained by slow diffusion of $\mathrm{Et}_{2} \mathrm{O}$ into a solution of 3 in $\mathrm{CH}_{2} \mathrm{Cl}_{2}$. The copper complex 3 recrystallizes in the space group $P \overline{1}$ (no. 2) with two independent metal complexes and additional solvent molecules in the asymmetric 


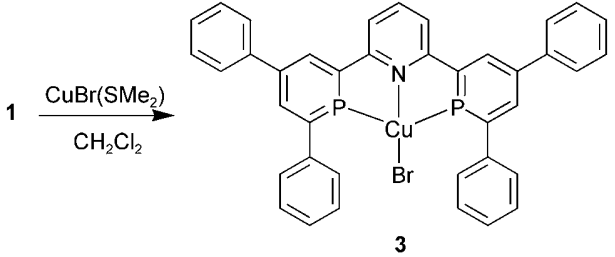

Scheme 2. Preparation of $\mathrm{Cu}$-complex $\mathbf{3}$.

unit. The molecular structure of one independent molecule is depicted in Figure 4 along with selected bond lengths and angles. Ligand $\mathbf{1}$ coordinates in a $\kappa^{3}(\mathrm{P}, \mathrm{N}, \mathrm{P})$ fashion to the metal center, while the fourth coordination site of $\mathrm{Cu}^{\mathrm{I}}$ is occupied by the $\mathrm{Br}^{-}$anion. The tetrahedral environment of $\mathrm{Cu}^{\mathrm{I}}$ further enforces a non-coplanarity of the three heterocycles leading to inter-planar angles for the P-heterocycles and the N-heterocycle between $25.5(2)$ and 31.4(2) .

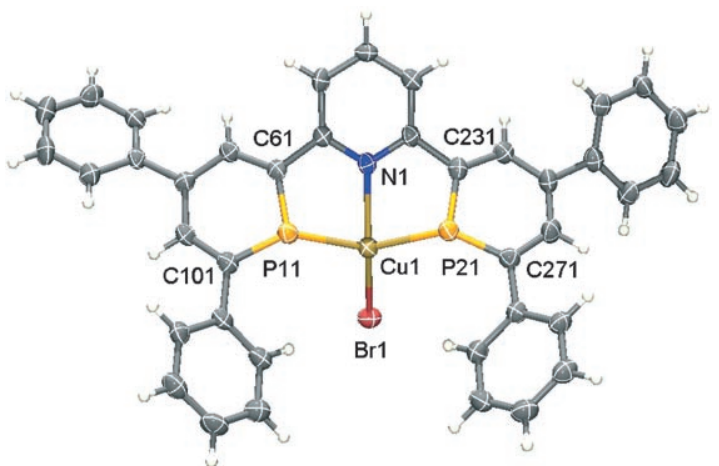

Figure 4. Molecular structure of $\mathbf{3}$ in the crystal. Displacement ellipsoids are shown at the $50 \%$ probability level. Only one independent molecule is shown. Selected bond lengths $[\AA]$ and angles $\left[{ }^{\circ}\right.$ (second molecule in square brackets): P11-C101 1.726(4) [1.728(4)], P11-C61 1.743(4) [1.733(4)], P21-C271 1.734(4) [1.726(4)], P21-C231 1.738(4) [1.733(4)], Cu1-P11 2.2522(13) [2.2757(12)], Cu1-P21 2.2641(12) [2.2719(12)], Cu1-N1 2.101(3) [2.079(3)], Cu1-Br1 2.3344(7) [2.3222(7)], C101-P11C61 103.09(19) [103.19(19)], C271-P21-C231 102.63(19) [103.06(19)], P11-Cu1-P21 137.20(5) [138.81(5)], N1-Cu1-Br1; 134.85(9) [135.07(9)].

A remarkable feature of the "butterfly" structure of $\mathbf{3}$ is the unusual non-directional coordination mode of the two phosphinine ligands, which ultimately allows coordination of the ligand to a metal with distorted tetrahedral geometry: The metal atom is no longer located in the ideal axis of the phosphorus lone pairs. Instead, the $\mathrm{Cu}-\mathrm{P}$ vectors significantly deviate from the plane defined by the heterocyclic rings by $28.20(15)$ to $33.06(14)^{\circ}$ (Figure 5 , front view).

The $\mathrm{Cu}-\mathrm{N}$ vectors form angles of $8.28(18)$ and $9.8(2)^{\circ}$ with the corresponding pyridine planes and are thus approximately coplanar. Additionally, the $\mathrm{Cu}$ atom is clearly shifted towards the nitrogen atom resulting in $\mathrm{Cu}-\mathrm{N}$ distances of 2.101(3) and 2.079(3) $\AA$, while the $\mathrm{Cu}-\mathrm{P}$ distances are in the range of 2.2522(13)-2.2757(12) $\AA$. Interestingly, and in contrast to our observations the corresponding complex (I) $\mathrm{Cu}^{\mathrm{I}} \mathrm{Br}$ bearing the diphosphine-based PNP-pincer ligand

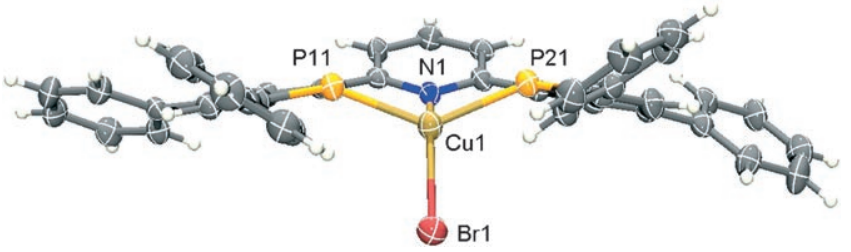

Figure 5. Molecular structure of $\mathbf{3}$ in the crystal (front view). Displacement ellipsoids are shown at the $50 \%$ probability level. Only one independent molecule is shown.

(Figure $2, \mathrm{R}=t \mathrm{Bu}$ ) lacks in any $\mathrm{Cu}-\mathrm{N}$ bonding. ${ }^{[13]}$ This phenomenon can be attributed to the much stronger donor character of phosphines in comparison to phosphinines, which, along with the sterically demanding $t \mathrm{Bu}$ groups obviously prevents coordination of the pyridine donor to the $\mathrm{Cu}^{\mathrm{I}}$ center in this particular complex.

The coordination behaviour of $\mathbf{1}$ can be rationalized by the pronounced spherical character of the phosphorus lonepair in phosphinines and the particular shape of the LUMO, $\mathrm{HOMO}$ and $\mathrm{HOMO}^{-1}$, which are responsible for $\pi$-back donation and $\pi$-donor contributions, respectively (see Figure 3). The resulting electronic situation apparently permits coordination to the $\mathrm{Cu}^{\mathrm{I}}$ center resulting in the observed unusual coordination geometry. ${ }^{[18]}$ Since the electronic properties of $\mathbf{1}$ are rather different compared to terpyridine it is therefore not surprising that complementary $\mathrm{Cu}^{\mathrm{I}}(\mathrm{tpy})$ complexes have not been described in literature so far. The facile complexation of the $\mathrm{Cu}^{\mathrm{I}} \mathrm{Br}$ fragment by ligand $\mathbf{1}$ can qualitatively be explained by the fact that the "soft" $\mathrm{Cu}^{\mathrm{I}}$ center is much better stabilized by the two $\pi$-accepting phosphinine ligands rather than by pyridine ligands in terpyridine ${ }^{[19,20]}$ Consequently, these two ligands exhibit a very different coordination behaviour.

Although phosphinines possess a rich and versatile coordination chemistry this uncommon geometry has so far only been observed in the $\mathrm{Cu}^{\mathrm{I}}$ complex containing the silacalix[3]-phosphinine macrocyclic ligand and in $\mathrm{Cu}(\mathrm{tmbp})-$ $\left(\mathrm{PPh}_{3}\right)_{2} \mathrm{BF}_{4}$ bearing the bidentate bipyridine analogue $4,4^{\prime}-$ 5,5'-tetramethyl-2,2'-bisphosphinine (tmbp). ${ }^{[21]}$ Due to the rather long $\mathrm{P}-\mathrm{Cu}$ bond lengths in the latter compound (2.3273(9); 2.3286(9) ^) the interaction between the copper center and the bisphosphinine ligand has been described as relatively weak. On the other hand, the $\mathrm{P}-\mathrm{Cu}$ bond lengths in $\mathbf{3}$ are significantly shorter $(2.2522(13)-2.2757(12) \AA)$. They are in the range of $\mathrm{Cu}-\mathrm{P}$ bond lengths observed in the very few $\mathrm{Cu}$-phosphinine complexes reported in literature and in which the $\mathrm{Cu}$ atom is located in the ideal axis of the phosphorus lone pair. ${ }^{[22]}$ Moreover, the $\mathrm{P}-\mathrm{Cu}$ and $\mathrm{N}-\mathrm{Cu}$ distances in $\mathbf{3}$ are comparable with the ones observed in the $\mathrm{Cu}^{\mathrm{I}}$ complex $[\mathrm{Cu}(\mathrm{MeCN})(\mathrm{pnp})] \mathrm{PF}_{6} \quad(\mathrm{pnp}=2,6$-bis(2-phosphaethenyl)pyridine, III) reported by Hayashi et al. ${ }^{[23]}$ The values of the $\mathrm{P}=\mathrm{C}$ bond lengths and C-P-C angles in $\mathbf{3}$ are comparable to the values of uncomplexed 2,4,6-triaryl-substituted phosphinines. ${ }^{[3 \mathrm{~d}, \mathrm{e}]}$

Another interesting feature of $\mathbf{3}$ is the dimer formation by intermolecular $\pi-\pi$ stacking interactions between the pyri- 
dine rings of the two independent metal complexes. The two molecules are arranged in such a way that the two $\mathrm{Br}^{-}$ligands are pointing in opposite directions, resulting in a distance of $3.517 \AA$ between the centers of the nearly parallel pyridine rings (Figure 6).

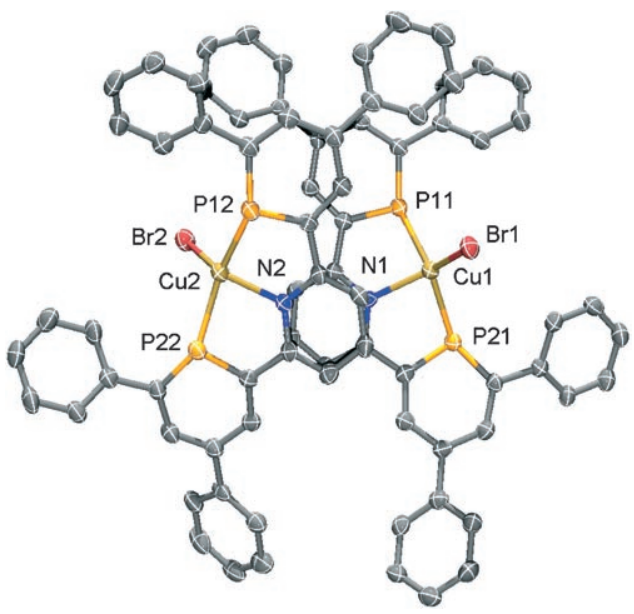

Figure 6 . Dimer formation by $\pi-\pi$ stacking interactions between the two independent metal complexes of $\mathbf{3}$. Hydrogen atoms are omitted for clarity.

In summary, we have developed a synthetic access to a novel neutral PNP-pincer ligand containing two phosphinine donors and a bridging pyridine moiety. In contrast to its terpyridine analogue facile coordination of this tridentate ligand towards a neutral $\mathrm{Cu}^{\mathrm{I}}$ center was observed. The corresponding $\mathrm{Cu}^{\mathrm{I}} \mathrm{Br}$ complex was characterized crystallographically and revealed a distorted tetrahedral coordination geometry of the metal center as a result of an unusual coordination mode of the two phosphinine ligands. Due to the presence of electronically rather inequivalent donor atoms, we anticipate that this novel ligand represents a new class of $\pi$-accepting PNP-pincer systems. This is expected to lead to transition-metal complexes with new properties and applications, especially in homogeneous catalysis and as optoelectronic devices in the near future. Further studies on this subject are currently carried out in our laboratories.

\section{Acknowledgements}

This work was supported in part (M.L., A.L.S.) by the Council for the Chemical Sciences of the Netherlands Organization for Scientific Research (CW-NWO).

Keywords: coordination chemistry • copper • density functional calculations $\cdot$ heterocycles $\cdot$ phosphorus

[1] a) G. Märkl, Angew. Chem. 1966, 78, 907; b) A. J. Ashe III, J. Am. Chem. Soc. 1971, 93, 3293.
[2] For recent reviews see: a) C. Müller, D. Vogt, Dalton Trans. 2007, 5505-5523; b) P. Le Floch, Coord. Chem. Rev. 2006, 250, 627-681; c) F. Mathey, P. Le Floch, Sci. Synth. 2005, 15, 1097-1155; d) F. Mathey, Angew. Chem. 2003, 115, 1616-1643; Angew. Chem. Int. Ed. 2003, 42, 1578-1604; e) P. Le Floch, F. Mathey, Coord. Chem. Rev. 1998, 179-180, 771-791.

[3] a) C. Müller, E. A. Pidko, A. J. P. M. Staring, M. Lutz, A. L. Spek, R. A. van Santen, D. Vogt, Chem. Eur. J. 2008, 14, 4899-4905; b) C. Müller, Z. Freixa, M. Lutz, A. L. Spek, D. Vogt, P. W. N. M. van Leeuwen, Organometallics 2008, 27, 834-838; c) C. Müller, E. A. Pidko, D. Totev, M. Lutz, A. L. Spek, R. A. van Santen, D. Vogt, Dalton Trans. 2007, 5372-5375; d) C. Müller, D. Wasserberg, J. J. M. Weemers, E. A. Pidko, S. Hoffmann, M. Lutz, A. L. Spek, S. C. J. Meskers, R. A. Janssen, R. A. van Santen, D. Vogt, Chem. Eur. J. 2007, 13, 4548-4559; e) C. Müller, M. Lutz, A. L. Spek, D. J. Vogt, J. Chem. Crystallogr. 2006, 36, 869-874; f) C. Müller, L. Guarrotxena-Lopéz, H. Kooijman, A. L. Spek, D. Vogt, Tetrahedron Lett. 2006, 47, 2017-2020.

[4] B. Breit, R. Winde, T. Mackewitz, R. Paciello, K. Harms, Chem. Eur. J. 2001, 7, 3106-3121.

[5] For the synthesis of substituted terpyridines starting from diacetylpyridine see: E. C. Constable, E. Figgemeier, I. A. Hougen, C. E. Housecroft, M. Neuburger, S. Schaffner, L. A. Whall, Dalton Trans. 2005, 1168-1175.

[6] J. W. Ellis, K. N. Harrison, P. A. T. Hoye, A. G. Orpen, P. G. Pringle, M. B. Smith, Inorg. Chem. 1992, 31, 3026-3033.

[7] E. Niecke, H. Westermann, Synthesis 1988, 330.

[8] For the $\mathrm{PPh}_{2^{-}}$and $\mathrm{PR}_{2}$-based PNP ligands see for example: a) $\mathrm{C}$. Hahn, M. Cucciolito, A. Vitagliano, J. Am. Chem. Soc. 2002, 124, 9038-9039; b) R. J. Trovitch, E. Lobkovsky, P. J. Chirik, Inorg. Chem. 2006, 45, 7252-7260; c) S. M. Kloek, D. M. Heinekey, K. I. Goldberg, Angew. Chem. 2007, 119, 4820-4822; Angew. Chem. Int. Ed. 2007, 46, 4736-4738; d) M. Feller, E. Ben-Ari, T. Gupta, L. J. W. Shimon, G. Leitus, Y. Diskin-Posner, L. Weiner, D. Milstein, Inorg. Chem. 2007, 46, 10479-10490; e) B. M. Cochran, F. E. Michael, J. Am. Chem. Soc. 2008, 130, 2786-2792.

[9] The DFT calculations were performed at B3LYP/6-31Gd level of theory. Further computational details and the visualization of a range of molecular orbitals of $\mathbf{3}$ can be found in the Supporting Information for comparison.

[10] Gaussian 03 (Revision B.05), M. J. Frisch, G. W. Trucks, H. B. Schlegel, G. E. Scuseria, M. A. Robb, J. R. Cheeseman, J. A. Montgomery, Jr., T. Vreven, K. N. Kudin, J. C. Burant, J. M. Millam, S. S. Iyengar, J. Tomasi, V. Barone, B. Mennucci, M. Cossi, G. Scalmani, N. Rega, G. A. Petersson, H. Nakatsuji, M. Hada, M. Ehara, K. Toyota, R. Fukuda, J. Hasegawa, M. Ishida, T. Nakajima, Y. Honda, O. Kitao, H. Nakai, M. Klene, X. Li, J. E. Knox, H. P. Hratchian, J. B. Cross, C. Adamo, J. Jaramillo, R. Gomperts, R. E. Stratmann, O. Yazyev, A. J. Austin, R. Cammi, C. Pomelli, J. W. Ochterski, P. Y. Ayala, K. Morokuma, G. A. Voth, P. Salvador, J. J. Dannenberg, V. G. Zakrzewski, S. Dapprich, A. D. Daniels, M. C. Strain, O. Farkas, D. K. Malick, A. D. Rabuck, K. Raghavachari, J. B. Foresman, J. V. Ortiz, Q. Cui, A. G. Baboul, S. Clifford, J. Cioslowski, B. B. Stefanov, G. Liu, A. Liashenko, P. Piskorz, I. Komaromi, R. L. Martin, D. J. Fox, T. Keith, M. A. Al-Laham, C. Y. Peng, A. Nanayakkara, M. Challacombe, P. M. W. Gill, B. Johnson, W. Chen, M. W. Wong, C. Gonzalez, J. A. Pople, Gaussian, Inc., Pittsburgh, PA, 2003.

[11] A. Jouaiti, M. Geoffroy, G. Bernardinelli, Tetrahedron Lett. 1992, 33, 5071.

[12] S. Ekici, D. Gudat, M. Nieger, L. Nyulaszi, E. Niecke, Angew. Chem. 2002, 114, 3515-3519; Angew. Chem. Int. Ed. 2002, 41, 33673371.

[13] J. I. van der Vlugt, E. A. Pidko, D. Vogt, M. Lutz, A. L. Spek, A. Meetsma, Inorg. Chem. 2008, 47, 4442-4444.

[14] G. Kickelbick, K. Matyjaszewski, Macromol. Rapid Commun. 1999, 20, 341-346.

[15] a) A. Onoda, K. Kawakita, T. Okamura, H. Yamamoto, N. Ueyama, Acta Crystallogr. E, 2003, 59, m266 m267; b) E. W. Ainscough, A. M. 
Brodie, S. L. Ingham, J. M. Waters, J. Chem. Soc. Dalton Trans. 1994, 215-220.

[16] H. Feng, X.-P. Zhou, T. Wu, D. Li, Y.-G. Yin, S. W. Ng, Inorg. Chim. Acta 2006, 359, 4027-4035.

[17] a) E. C. Constable, Chem. Soc., Rev. 2007, 36, 246-253; b) E. C. Constable, Adv. Inorg. Chem. 1986, 30, 69.

[18] See also: M. T. Reetz, E. Bohres, R. Goddard, M. C. Holthausen, W. Thiel, Chem. Eur. J. 1999, 5, 2101-2108.

[19] Qualitatively, Pearson's HSAB concept might be considered for describing the coordination behaviour of ligand $\mathbf{1}$ in comparison to terpyridine: The "softer" phosphorus donor in phosphinines compared to the "harder" nitrogen donor in pyridines allows coordination to the "soft" $\mathrm{Cu}^{\mathrm{I}}$ center under formation of complex 3 .
[20] R. G. Pearson, J. Am. Chem. Soc. 1963, 85, 3533-3539.

[21] a) A. Moores, N. Mézailles, N. Maigrot, L. Ricard, F. Mathey, P. Le Floch, Eur. J. Inorg. Chem. 2002, 2034-2039; b) P. Le Floch, L. Ricard, F. Mathey, Bull. Soc. Chim. Fr. 1996, 133, 691-696.

[22] a) M. Shiotsuka, T. Tanamachi, T. Urakawa, M. Munakata, Y. J. Matsuda, Supramol. Chem. 2002, 2, 211-217; b) M. Shiotsuka, Y. Matsuda, Chem. Lett. 1994, 351-354; c) N. Mézailles, P. Le Floch, K. Waschbüsch, L. Ricard, F. Mathey, C. P. Kubiak, J. Organomet. Chem. 1997, 541, 277-283.

[23] A. Hayashi, M. Okazaki, F. Ozawa, Organometallics 2007, 26, 52465249 .

Received: July 3, 2008 Published online: August 21, 2008 